\title{
Health professionals' sick absenteeism and determinants of incapacity leave approvals in a South African provincial health department
}

Roshnee Ramsamy ( $\sim$ rosh2811@gmail.com )

University of the Witwatersrand School of Public Health https://orcid.org/0000-0001-6666-4545

Prudence Ditlopo

University of the Witwatersrand School of Public Health

Laetitia Rispel

University of the Witwatersrand School of Public Health

\section{Research}

Keywords: absenteeism, incapacity leave, sickness absenteeism, health worker performance, health professional, South Africa

Posted Date: January 4th, 2021

DOI: https://doi.org/10.21203/rs.3.rs-136797/v1

License: (a) (1) This work is licensed under a Creative Commons Attribution 4.0 International License. Read Full License 


\section{Abstract}

\section{Background}

A well-performing health workforce is critical to the successful implementation of universal health coverage. Sickness absenteeism influences health worker performance, with potentially negative consequences for quality of patient care and staff morale. Within the South African public sector, incapacity leave is additional sick leave granted at the discretion of the employer.

Objectives

The aim of this study was to examine approved incapacity leave and its determinants among health professionals in a provincial health department in South Africa.

Methodology

Electronic records of approved incapacity leave absences of health professionals employed in the Gauteng Department of Health (GDoH) were obtained from the government's Personnel Salary Administration System. The period of analysis was 1 January 2016 until 31 December 2016. A structured record review form was used to extract demographic, occupational and medical information on each approved leave episode. STATA ® 15 was used for descriptive and multivariate statistical analysis.

Results

In 2016, the GDoH approved the incapacity leave of 518 health professionals. The mean age of health professionals with incapacity leave was 46 years ( $S D \pm 10.2$ years). Professional nurses accounted for $41.5 \%$ of incapacity leave approvals. The main medical reasons for incapacity leave episodes were mental disorders (12.8\%) and musculoskeletal disorders (12.0\%). The risk factors for incapacity leave among health professionals were: female, 35 years and older, from district hospitals and working in the Sedibeng health district $(p<0.001)$. The odds of incapacity leave was three times higher for health professionals who were older than 45 years (45 to 54 years - adjusted odds ratio (AOR) $3.095 \% \mathrm{Cl} 2.3$ 4.0) ( $\geq 55$ years - AOR $3.195 \% \mathrm{Cl} 2.3-4.3$ ). The odds of incapacity leave among health professionals was highest for those working in the Sedibeng health district (AOR $2.295 \% \mathrm{Cl} 1.5-3.3$ ).

\section{Conclusions}

Sickness absenteeism is complex and influenced by individual, workplace and health system factors. The study findings suggest the need to improve the management of incapacity leave in the GDoH, through inter alia, improved information systems, monitoring of sickness absenteeism and the creation of positive practice environments.

\section{Introduction}


Human resources for health $(\mathrm{HRH})$ are a prerequisite for the achievement of universal health coverage (UHC) and improved population health outcomes [1]. There is increasing scholarly attention on the performance and the efficient utilisation of $\mathrm{HRH}$ [1]. Absenteeism which is defined as the absence from a duty or an obligation, is an important indicator of individual staff performance [2,3]. Absenteeism gives rise to loss in productivity and results in the indirect wastage of valuable HRH [4]. In Sub-Saharan Africa, this type of wastage exacerbates staff shortages and further compromises weak health systems [4]

Sickness absenteeism is unplanned absence, and is defined as an absence from work, which the employee associates with illness or injury $[2,5,6]$. While sick absenteeism is a problem in many sectors and countries $[5,6]$, it is of critical importance in the health sector, affecting both the quality of patient care and staff morale [2, 7].

In South Africa, evidence suggests that sick absenteeism affects the public health care system negatively, with reports of high rates of absenteeism and its associated costs, sick leave abuse, and poor management of sick leave $[8,9]$. The Public Sector Leave Policy provides for paid sick leave of 36 working days in a cycle of three years [10]. All public sector employees who have exhausted their sick leave within the sick leave cycle and are medically certified to be absent from work, are able to apply for temporary incapacity leave with full pay [10].

Higher rates of sickness absenteeism have been reported among health professionals because of the nature of the caring professions, adverse working conditions, long working hours, decreased autonomy and insufficient support from their colleagues and supervisors [5]. Estimates suggest that around $7 \%$ of health workers experience at least one sick leave episode per week [11].

Numerous studies have demonstrated complex and contradictory associations between sick absenteeism and a range of demographic, occupational and organisational factors $[12,13]$. These studies have found associations between sickness absenteeism and gender and age, and the type of health professional $[2,6,14]$.

In South Africa, a 2008 study found a $48.8 \%$ absence rate among all the employees of four hospitals in the Gauteng Province of South Africa [15]. In contrast, a 2014 study found 6\% sickness absenteeism among nursing staff a large, central hospital in the Western Cape Province [16]. In 2017, the provincial legislature (parliament) in Gauteng raised concerns that almost $40 \%$ of the applications for incapacity leave in the Gauteng Department of Health (GDoH) during 2014 and 2016, were absences of one or two days, at an estimated costs of R14 million (823 528 US dollars; 1USD = R17) [17]. Hence, this study was conducted to generate new knowledge on incapacity leave and its determinants, given the strategic importance of the Gauteng Province in South Africa. Gauteng is the most densely populated province in South Africa, generating close to $40 \%$ of the country's gross domestic product, and with a quarter of the South African population [18].

The purpose of the study was two-fold: firstly, to describe the demographic and occupational characteristics of health professionals with approved incapacity leave, and the medical reasons for this 
type of leave; and secondly to determine whether there was an association between approved incapacity leave and the demographic and occupational variables.

\section{Methods}

\section{Study setting}

The study setting was the GDoH, which is one of the largest public health departments in South Africa. In 2016, the GDoH consisted of a head office, four central hospitals, three tertiary hospitals, nine provincial regional hospitals, 11 district hospitals, a medical supplies depot, sub-district offices, four nursing training colleges, emergency medical services and 373 clinics [19].

There were five district offices, with each district having the same boundaries as the municipalities-these were City of Johannesburg, City of Tshwane, Ekurhuleni, West Rand and Sedibeng.

\section{Study population and eligibility}

The study population comprised of all health professionals employed in the GDoH who had approved incapacity leave in 2016. In the study year, there were 68770 employees, and 46812 health professionals, who are all individuals with formal health training such as doctors, nurses and rehabilitation therapists [19].

The exclusion criteria applied in the study were: a) incapacity leave records for non-health professionals in the $\mathrm{GDoH}, \mathrm{b}$ ) incapacity leave records which occurred outside the study period of 1 January 2016 to 31 December 2016, c) incapacity leave records which were processed by the GDoH and deemed to be declined (invalid) in terms of PILIR or not processed by the time of data collection and d) all other forms of leave such as sick leave, annual leave and leave without pay.

\section{Study period}

This was a record review of all approved incapacity leave for the period 1 January 2016 to 31 December 2016. The study period was selected due to the increase in sick leave and disability leave when compared to the previous calendar year [19]. In addition, 2016 was the start of a new sick leave cycle.

\section{Data curation}

The government's Personnel Salary Administration System (PERSAL) contains electronic incapacity leave records for all public service employees. The GDoH provided demographic and occupational data of all employees for the 2016/2017 financial year. The GDoH provided the initial PERSAL dataset of approved incapacity leave for 2016. This information on incapacity leave was verified and supplemented by an electronic PERSAL dataset received from the National Treasury. All the records were carefully matched through a multi-step process.

\section{Data collection}


The research team designed a structured record review form to extract information of approved incapacity leave absences of health professionals employed in the GDoH. The form was modelled on the incapacity leave application forms used in South Africa's public sector [10]. The form captured demographic characteristics (e.g. age and gender), occupational characteristics (e.g. salary level, category of health professional, etc.), and medical condition (according to ICD-10 classification). The salary bands and salary levels within each band in the South African public sector, are shown in the Table 1.

Table 1

Salary bands of public sector employees in South Africa

\begin{tabular}{|lll|}
\hline Salary band & \multicolumn{2}{l|}{ Average personnel cost per employee } \\
\cline { 2 - 3 } & (R'000) & 1USD = R17 \\
\hline Lower skilled and Skilled (<level 6) & 209427,27 & 12319,25 \\
\hline Highly skilled production (Levels 6-8) & 296428,49 & 17436,97 \\
\hline Highly skilled supervision (Levels 9-12) & 501944,56 & 29526,15 \\
\hline
\end{tabular}

Source: Gauteng Department of Health [19]

Continuous variables were recoded into categorical variables for descriptive and reporting purposes. Categories were defined according to the distribution of the data. The study variables are shown in Table 2.

Table 2

Description of study variables

\begin{tabular}{|ll|}
\hline Variable & Description of categories \\
\hline Age & $<35$ years; 35 to 44 years; 45 to 54 years and $\geq 55$ years \\
\hline $\begin{array}{l}\text { Years of service (indicating the } \\
\text { number of years employed at } \\
\text { the GDoH) }\end{array}$ & $\leq 10$ years; 11 to 20 years; 21 to 30 years and $\geq 31$ years \\
\hline Salary levels & $<$ level 6 ; levels 6 to 9 and levels 10 to 16 \\
\hline $\begin{array}{l}\text { Job titles (according to the type } \\
\text { of work) }\end{array}$ & $\begin{array}{l}\text { Managers; medical staff; professional nurses; staff nurses; } \\
\text { nursing assistants and allied health professionals }\end{array}$ \\
\hline $\begin{array}{l}\text { Type of service/facility } \\
\text { Central and tertiary hospitals; regional hospitals; district hospitals; } \\
\text { specialised hospitals; primary health care and other types of } \\
\text { facility/services }\end{array}$ \\
$\begin{array}{l}\text { Medical reasons' for incapacity } \\
\text { leave }\end{array}$ & $\begin{array}{l}\text { ICD-10 categories from the World Health Organization (WHO) } \\
\text { website (https://icd.who.int/browse10/2016/en) }\end{array}$ \\
\hline
\end{tabular}

The outcome measure approved incapacity leave was dichotomised and coded as either 0 or 1 indicating the absence or presence of the outcome. 


\section{Data analysis}

The data on the incapacity leave were described using frequencies and proportions. The association between incapacity leave episodes among health professionals in the GDoH (outcome variable) and the demographic and occupational characteristics (exposure variables), were first examined through a bivariate analysis. The differences between groups were evaluated using the Chi-square test. All variables that were significant at a $20 \%$ level were included in the logistic regression models. Cross tabulations and variance inflation factor (VIF) were performed to determine collinearity between covariate variables such as 'Salary levels' and 'Job title'. The variable on 'Salary level' was excluded as it was related to the variable 'Job title'. No weighting was done as the study focused on all health professionals with approved incapacity leave and no sampling was done.

Multiple logistic regression models were constructed to investigate the independent effects of the exposure variables (demographic factors and occupational factors) upon the probability of incapacity leave among health professionals in the GDoH. The full logistic regression model included 'Age', 'Gender', 'Years of service', 'Job title', 'Type of service' and 'Health district'. The results of the logistic regression are presented in the form of adjusted odds ratios with $95 \%$ confidence intervals $(95 \% \mathrm{Cl})$.

\section{Ethical considerations}

The Human Research Ethics Committee (Medical) of the University of the Witwatersrand, Johannesburg provided ethical approval for the study (M180522). Further permission to conduct the study was obtained from the GDoH Research Committee. The information was treated confidentially, and the dataset contained no personal identifiers.

\section{Results}

\section{Demographic and occupational characteristics}

In 2016, the total number of health professionals in the GDoH was 46 812, of which 518 (1.1\%) had 1155 episodes of approved incapacity leave. Descriptive statistics are shown in Table 3. Among those health professionals with approved incapacity leave, the majority were female (91.3\%). The mean age of health professionals with approved incapacity leave was 46 years ( \pm 10.2 years) with just over a third of between the ages of 45 to 54 years (35.9\%). Among the health professionals with approved incapacity leave, the majority (61.8\%) had between 1 and 10 years of service. The highest proportion of health professionals with incapacity leave were from salary levels 6 to 9 (51.5\%). Professional nurses accounted for $41.5 \%$ of health professionals with incapacity leave, while all categories of nurses accounted for $78 \%$ of health professionals with approved incapacity leave. In terms of place of employment, most health professionals with incapacity leave were from the City of Johannesburg health district (44.8\%) and employed at central and tertiary hospitals (42.7\%). 
Table 3

Demographic and occupational characteristics of GDoH health professionals and those with approved incapacity leave

\section{GDoH health professionals GDoH health professionals with approved $(\mathrm{N}=46812)$ incapacity leave $(n=518)$}

$\begin{array}{llll}\text { Number }(n) & \% & \text { Number }(n) & \%\end{array}$

\section{Gender}

Female

38320

81.9

473

91.3

Male

8492

18.1

45

8.7

Age (grouped in years)

$\begin{array}{lllll}<35 \text { years } & 17952 & 38.4 & 93 & 18.0 \\ 35 \text { to } 44 \text { years } & 12749 & 27.2 & 116 & 22.4 \\ 45 \text { to } 54 \text { years } & 9843 & 21.0 & 186 & 35.9 \\ \geq 55 \text { years } & 6268 & 13.4 & 123 & 23.8 \\ \text { Age (mean } \pm \text { S.D.) } & 39( \pm 11.6) & & 46( \pm 10.2) & \end{array}$

Years of service (grouped in years)

\begin{tabular}{lllll}
1 to 10 & 35521 & 75.9 & 320 & 61.8 \\
11 to 20 & 5947 & 12.7 & 83 & 16.0 \\
21 to 30 & 3905 & 8.3 & 87 & 16.8 \\
$\geq 31$ & 1439 & 3.0 & 28 & 5.4 \\
\hline Median (IQR) & $6(1-10)$ & & $8(5-16)$ &
\end{tabular}

Salary levels (grouped)

\begin{tabular}{|c|c|c|c|c|}
\hline$<6$ & 18653 & 39.9 & 154 & 29.7 \\
\hline 6 to 9 & 17386 & 37.1 & 267 & 51.5 \\
\hline 10 to 16 & 10773 & 23.0 & 97 & 18.7 \\
\hline Median (IQR) & $7(4-9)$ & & $7(5-9)$ & \\
\hline \multicolumn{5}{|c|}{ Job title (grouped) } \\
\hline Managers & 2523 & 5.4 & 39 & 7.5 \\
\hline Medical staff & 6060 & 13.0 & 15 & 2.9 \\
\hline $\begin{array}{l}\text { Professional } \\
\text { Nurses }\end{array}$ & 16715 & 35.7 & 215 & 41.5 \\
\hline
\end{tabular}




\begin{tabular}{|c|c|c|c|c|}
\hline & \multicolumn{2}{|c|}{$\begin{array}{l}\text { GDoH health professionals } \\
(\mathrm{N}=46812)\end{array}$} & \multicolumn{2}{|c|}{$\begin{array}{l}\text { GDoH health professionals with approved } \\
\text { incapacity leave }(n=518)\end{array}$} \\
\hline & Number (n) & $\%$ & Number (n) & $\%$ \\
\hline Staff Nurses & 7509 & 16.0 & 98 & 18.9 \\
\hline Nursing Assistants & 6825 & 14.6 & 91 & 17.6 \\
\hline $\begin{array}{l}\text { Allied health } \\
\text { professionals }\end{array}$ & 7180 & 15.3 & 60 & 11.6 \\
\hline \multicolumn{5}{|l|}{ Health district } \\
\hline Ekurhuleni & 7243 & 15.5 & 56 & 10.8 \\
\hline Johannesburg & 19525 & 41.7 & 232 & 44.8 \\
\hline Sedibeng & 2515 & 5.4 & 47 & 9.0 \\
\hline Tshwane & 14136 & 30.2 & 153 & 29.5 \\
\hline West Rand & 3393 & 7.3 & 30 & 5.8 \\
\hline \multicolumn{5}{|c|}{ Type of facility/service } \\
\hline $\begin{array}{l}\text { Central \& Tertiary } \\
\text { hospitals }\end{array}$ & 17463 & 37.3 & 221 & 42.6 \\
\hline Regional hospitals & 7695 & 16.4 & 67 & 12.9 \\
\hline District hospitals & 4368 & 9.3 & 78 & 15.1 \\
\hline $\begin{array}{l}\text { Specialised } \\
\text { hospitals }\end{array}$ & 2166 & 4.6 & 25 & 4.8 \\
\hline $\mathrm{PHC}$ & 5265 & 11.3 & 72 & 13.9 \\
\hline $\begin{array}{l}\text { Other types of } \\
\text { facility/service }\end{array}$ & 9855 & 21.0 & 55 & 10.6 \\
\hline
\end{tabular}

\section{Medical reasons for approved incapacity leave}

There were 1155 approved incapacity leave episodes taken by 518 health professionals in the GDoH during the period under review. The proportion of health professionals with more than one episode of approved incapacity leave was $47.1 \%$.

Table 4 presents the medical reasons for these incapacity leave episodes. The two leading medical reasons for incapacity leave episodes were mental and behavioural disorders $(12.8 \%)$ and musculoskeletal disorders (12.0\%). These two ICD-10 classifications collectively accounted for a quarter of approved incapacity leave episodes $(n=287)$. The third main medical reasons for incapacity leave among health professionals were diseases of the respiratory system and injury, poisoning and certain other consequences of external causes, each accounting for $8.8 \%$ of approved incapacity leave episodes. 
Table 4

Medical reasons for approved incapacity leave episodes

\section{ICD-10 Classifications}

\begin{tabular}{|c|c|c|}
\hline & \\
\hline & $\mathbf{n}$ & $\%$ \\
\hline Mental and behavioural disorders & 148 & 12.8 \\
\hline Diseases of the musculoskeletal system and connective tissue & 139 & 12.0 \\
\hline Diseases of the respiratory system & 102 & 8.8 \\
\hline Injury, poisoning and certain other consequences of external causes & 102 & 8.8 \\
\hline Surgery & 95 & 8.2 \\
\hline Diseases of the genitourinary system & 92 & 8.0 \\
\hline Factors influencing health status and contact with health services & 86 & 7.5 \\
\hline Neoplasms & 86 & 7.5 \\
\hline Diseases of the digestive system & 68 & 5.9 \\
\hline Diseases of the circulatory system & 62 & 5.4 \\
\hline $\begin{array}{l}\text { Symptoms, signs and abnormal clinical and laboratory findings, not } \\
\text { elsewhere classified }\end{array}$ & 45 & 3.9 \\
\hline Diseases of the nervous system & 35 & 3.0 \\
\hline Certain infectious and parasitic diseases & 31 & 2.7 \\
\hline Diseases of the eye and adnexa & 17 & 1.5 \\
\hline Endocrine, nutritional and metabolic diseases & 17 & 1.5 \\
\hline Diseases of the skin and subcutaneous tissue & 12 & 1.0 \\
\hline Diseases of Pregnancy, Childbirth and the Puerperium & 11 & 1.0 \\
\hline Diseases of the ear and mastoid process & 4 & 0.4 \\
\hline $\begin{array}{l}\text { Diseases of the blood and blood-forming organs and certain } \\
\text { disorders involving the immune mechanism }\end{array}$ & 3 & 0.3 \\
\hline
\end{tabular}

The proportion of incapacity leave episodes due to mental and behavioural disorders was highest among health professionals 35 years and younger (33.8\%) and lowest among health professionals 55 years and older (12.2\%). Incapacity leave due to diseases of the musculoskeletal system was highest among health professionals 45 to 54 years old (55.4\%) followed by health professionals 55 years and older $(22.3 \%)$. Incapacity leave due to diseases of the respiratory system and injury were highest among health 
professionals in the 45 to 54 year age group (33.3\% and $36.3 \%$ respectively). Almost half of all incapacity leave related to neoplasms were for health professionals in the 45 to 54 year age category $(46.5 \%)$.

\section{Association between demographic and occupational characteristics and approved incapacity leave}

In the bivariate analysis, 'Age', 'Gender, 'Years of service', 'Salary level', 'Job title', 'Health district' and 'Type of service/facility' were all found to be independently associated with incapacity leave ( $p$ value $<0.001$ ). In the multivariate logistic regression, the risk factors for incapacity leave among health professionals were: 35 years and older and working in the Sedibeng health district $(p<0.001)$. Compared to the reference category, the odds of incapacity leave was three times higher for health professionals who were older than 45 years ( 45 to 54 years - adjusted odds ratio (AOR) $3.095 \%$ Cl 2.3-4.0) ( $\geq 55$ years - AOR 3.1 $95 \% \mathrm{Cl} 2.3-4.3$ ). Compared to the reference category, the odds of incapacity leave among health professionals was highest for those working in the Sedibeng health district (AOR $2.295 \% \mathrm{Cl} 1.5-3.2$ ).

The protective factors for incapacity leave among health professionals were male, medical staff and being employed at 'other' types of facilities/service. There were lower odds of incapacity leave among male health professionals (AOR $0.795 \% \mathrm{Cl} 0.5-0.9$, p value 0.02 ) compared to females. The odds of incapacity leave was lowest among medical staff (AOR $0.395 \% \mathrm{Cl} 0.2-0.6$, p value $<0.001$ ). The results of the adjusted odds ratio of approved incapacity leave among health professionals in the GDoH are presented in Table 5. 
Table 5

Adjusted odds ratio of approved incapacity leave among health professionals in the GDoH

\begin{tabular}{|c|c|c|c|}
\hline Variables & ${ }^{*} \mathrm{AOR}$ & $p$ value & $95 \% \mathrm{Cl}$ \\
\hline \multicolumn{4}{|l|}{ Demographic variables } \\
\hline \multicolumn{4}{|l|}{ Age groups } \\
\hline$<35$ years & 1 & & \\
\hline 35 to 44 years & 1.5 & $<0.001$ & $1.2-2.0$ \\
\hline 45 to 54 years & 3.0 & $<0.001$ & $2.3-4.0$ \\
\hline$\geq 55$ years & 3.1 & $<0.001$ & $2.3-4.3$ \\
\hline \multicolumn{4}{|l|}{ Gender } \\
\hline Male & 0.7 & 0.02 & $0.5-0.9$ \\
\hline Female & 1 & & \\
\hline \multicolumn{4}{|l|}{ Occupational variables } \\
\hline \multicolumn{4}{|l|}{ Years of service groups } \\
\hline 1 to 10 years & 1 & & \\
\hline 11 to 20 years & 1.0 & 0.7 & $0.8-1.4$ \\
\hline 21 to 30 years & 1.2 & 0.2 & $0.9-1.6$ \\
\hline$\geq 31$ years & 1.0 & 0.9 & $0.7-1.6$ \\
\hline \multicolumn{4}{|l|}{ Job title groups } \\
\hline Manager & 1 & & \\
\hline Medical staff & 0.3 & $<0.001$ & $0.2-0.6$ \\
\hline Professional Nurse & 1.2 & 0.3 & $0.9-1.7$ \\
\hline Staff Nurse & 1.2 & 0.4 & $0.8-1.8$ \\
\hline Nursing Assistant & 1.3 & 0.3 & $0.8-1.9$ \\
\hline Allied health professionals & 1.1 & 0.6 & $0.7-1.7$ \\
\hline \multicolumn{4}{|l|}{ Health district } \\
\hline Ekurhuleni & 1 & & \\
\hline Johannesburg & 1.7 & $<0.001$ & $1.2-2.3$ \\
\hline
\end{tabular}

*Legend: *AOR, adjusted odds ratio. 


\begin{tabular}{|llll|}
\hline Variables & *AOR & p value & $95 \% \mathrm{Cl}$ \\
\hline Sedibeng & 2.2 & $<0.001$ & $1.5-3.2$ \\
\hline Tshwane & 1.3 & 0.1 & $0.9-1.8$ \\
\hline West Rand & 1.0 & 0.9 & $0.6-1.6$ \\
\hline Type of service groups & & & \\
\hline Central \& Tertiary hospitals & 1 & & \\
\hline Regional hospitals & 0.7 & 0.1 & $0.5-1.0$ \\
\hline District hospitals & 1.4 & 0.0 & $1.0-1.8$ \\
\hline Specialised hospitals & 1.0 & 0.9 & $0.6-1.5$ \\
\hline PHC & 0.8 & 0.2 & $0.6-1.1$ \\
\hline Other types of facility/service & 0.5 & $<0.001$ & $0.4-0.7$ \\
\hline *Legend: *AOR, adjusted odds ratio. & & \\
\hline
\end{tabular}

\section{Discussion}

In 2016, 518 (1.1\%) of the 46812 health professionals in the GDoH had approved incapacity leave. Other South African hospital studies reported much higher sickness absence rates of $6 \%$ among nurses [16] and $12.2 \%$ among all staff at a tertiary hospital [20]. The lower proportion of health professionals with incapacity leave in the present study could be due to differences in the study periods, study populations and/or methodologies. In addition, the year 2016 marked the beginning of a new sick leave cycle where all public sector employees would have had access to 36 days of sick leave. Incapacity leave can only be accessed once sick leave credits have been depleted and this could have contributed to the lower proportion of incapacity leave in the present study. Although there were 518 health professionals with approved incapacity leave, there were 1155 records incapacity leave episodes, with $47.1 \%$ of health professionals having more than one episode of incapacity leave during the period under review.

In this study, there were more female health professionals with approved incapacity leave $(91.3 \%)$ compared to male health professionals (8.7\%). These gender differences were found in other South African studies [8, 15], and in studies in high income countries [21, 22]. This can partly be explained by the feminisation of the health workforce [23], the reproductive health needs of women [24], and the disproportionate burden of care and family responsibilities [24] that fall on women.

Our study found that incapacity leave was lowest for health professionals under the age of 35 years and highest among health professionals who were between the ages of 45 to 54 years. The positive correlation between increasing age and sick absenteeism was also found in a Nigerian study among 
hospital workers and among older nurses in a study from India [25,26]. Thorsen et al. suggest that the higher long term absences among older age groups could be due to deteriorating health [22].

Our study found that nurses accounted for the highest proportion of health professionals with incapacity leave approvals. This could be because the majority of nurses are women, who were more likely to have approved incapacity leave. A 2015 study in Durban, South Africa found that frequent rotations of nurses to cover staff shortages and unsatisfactory working conditions contributed to high rates of absenteeism [27]. Similarly a study among Iranian nurses found that labour intensive situations and performing multiple jobs predisposed nurses to illnesses, requiring sickness absenteeism [28]. We found that medical doctors accounted for the lowest proportion of health professionals with approved incapacity leave. Other studies also reported lower rates of sickness absenteeism for doctors and physicians compared to nurses and auxiliary staff $[2,21,29,30]$. This could be due to underreporting of sickness absenteeism, early detection and self-management of illness by medical staff $[21,29]$ as well as lower workloads, compared to nurses.

Although the proportion of health professionals with approved incapacity leave was higher in central and tertiary hospitals, the odds ratio of health professionals with approved incapacity leave was higher in district hospitals, compared with other types of facilities in the GDoH. This means that fewer health professionals would be available to render the specialised services often provided at central and tertiary hospitals, thus compromising health service delivery. This finding of higher absenteeism at larger facilities is similar to a Kenyan study which found more health workers were absent at the larger district and sub-district facilities compared to the smaller health centres [2]. A possible explanation is that higher absenteeism at larger organisations could be due to bureaucracy where it may be 'easier' for health worker's actions to go by unnoticed [2].

Our study found that the leading medical reasons for incapacity leave episodes among health professionals were mental disorders (12.8\%) and musculoskeletal disorders $(12 \%)$. While in our study, only $8.8 \%$ of approved incapacity leave was related to respiratory conditions, other studies have found that respiratory tracts infections especially influenza to be the most frequent causes of sickness absenteeism among health workers [28, 31-33].

In our study, we found that incapacity leave episodes due to mental disorders was higher among the younger health professionals under the age of 35 years when compared with the older age groups. These results are consistent with other studies [34] and the findings suggest that this could be because younger employees may not necessarily have the skills to cope with stressful situations and high workloads compared to older employees [35].

Mollazadeh et al., postulated that high proportions of sick leave related to musculoskeletal disorders among health workers could be due to occupational hazards and ergonomic risk factors such as awkward postures, lifting or moving heavy patients, standing for long periods as well as increased work stress and poor team dynamics [28]. This study found that older health professionals between the ages of 45 to 54 years had the highest proportion of incapacity leave episodes related to musculoskeletal 
disorders. Similarly, a South African study by Olivier et al. who reviewed incapacity leave applications, reported that the mean age of nurses with incapacity leave related to musculoskeletal disorders specifically low back pain, was 48 years [36]. Our study found that musculoskeletal disorders were the leading reason for incapacity leave episodes taken by managers and physiotherapists; pharmacists and emergency medical staff. A systematic review found that allied health professionals were at risk of developing work related musculoskeletal disorders, and that the risk factors included younger therapists, fewer years of work experience and exposure to high levels of repetitive tasks [37].

The results of the logistic regression showed that the risk of approved incapacity leave was three times higher for health professionals 45 years and older and two times higher for health professionals employed in the Sedibeng health district. Other statistically significant predictors of approved incapacity leave among health professionals employed in the GDoH were being employed in the Johannesburg health district and at district hospitals. The increased odds of approved incapacity leave among health professionals employed in the Sedibeng health district could reflect the under-served nature of the district as it has the fewest number of health professionals among the five health districts in Gauteng. The implications would be that even fewer health professionals would be available to render effective service delivery and this could compromise the performance of the health system and ultimately the health outcomes of the population. The study finding suggests the need for the GDoH to address the inequity in the distribution of health professionals in the province.

The study is limited by the use of routine government statistics, which could be affected by irregular updating and/or contain missing or incomplete data $[8,16]$. The study was limited to health professionals' approved incapacity leave that occurred in 2016. The selection of only one year might have introduced a potential bias as incapacity leave which commenced prior to 2016 but ended in 2016 or incapacity leave which commenced in 2016 but ended in 2017 onwards were excluded. Finally, the study was restricted to health professionals employed in the $\mathrm{GDoH}$ and may not be generalisable to health professionals in other parts of South Africa's public health service.

There are several strengths to our study. The study makes an important scholarly contribution to the discourse on sick absenteeism and on health workforce performance. In studies on sickness absenteeism, the use of electronically recorded leave data is considered to be more accurate than relying on data from self-reported absence which could be influenced by recall bias. Another strength is that our study focused on medically certified incapacity leave for all public sector health professionals within a province. Finally, while studies on absenteeism in the South African public health sector have focused mainly on all types of absence (including annual leave) or only on sick leave, this study is one of the first to explore incapacity leave.

Our study findings provide an important baseline which could serve to evaluate trends in incapacity leave in the GDoH and in other provincial health departments. The study also demonstrates the value of analysing routinely collected information. It also points to the need to improve data quality of leave capturing, given the cost implications of sick absenteeism. 
The findings of this study suggest that there are factors at the individual, workplace and health system level such as age, job category and length of service, which influence absenteeism in the workplace. At the individual health worker level, health workers should be encouraged to participate in wellness and mental health support initiatives, manage their medical conditions through appropriate disease management programmes and actively seek assistance to cope and deal with work stressors such as burnout. At the workplace level, there should be regular awareness sessions to health workers informing them of the support and disease management programmes available to them at work. By creating specific mental health support programmes for health workers to participate in, such as support groups and counselling services, the workplace can assist the large number of health professionals who are utilising incapacity leave for mental health conditions. Newly appointed staff should be inducted and trained on leave management and provided with adequate support and supervision to ensure that they transition appropriately into the work environment. At the health system level, there should be clear guidelines and policies on interventions such as employee wellness programmes, which take care of the health and well-being of health workers employed in the department.

Considering that the majority of the health professional workforce within the GDoH are female, the study findings suggest that more efforts should be made to create a gender-sensitive work environment that takes account of the needs of working women. Work environments need to be changed through gender transformative policies that seek to address the underlying causes of gender inequities which contribute to shortages of health workers [23].

\section{Conclusion}

Health professionals are an integral part of the health system and they need to be available and responsive in order to meet the needs of the population they serve. The performance of the health workforce is critical to the realisation of UHC. Absenteeism among the health workforce influences the performance of the health system, ultimately impacting on population health. This study has provided empirical information on incapacity leave approvals among health professionals in the GDoH and can contribute to improving the management of leave due to illness. Such improved management is critical in light of the already limited resources and sub-optimal performance of the health care system in South Africa.

\section{Abbreviations}

GDoH: Gauteng Department of Health; AOR: Adjusted odds ratio; HRH: Human resources for health; UHC: universal health coverage, NHI: National Health Insurance; PSC: Public Service Commission; PILIR: Policy on incapacity leave and ill health retirement; PERSAL: Personnel and Salary System; PHC: Primary health care; LMIC: low- and middle-income countries.

\section{Declarations}




\section{Ethics approval}

Ethical approval for the study obtained from the Human Research Ethics Committee (Medical) of the University of the Witwatersrand, Johannesburg (M180522). Further permission to conduct the study was obtained from the GDoH Research Committee.

\section{Consent for publication}

Not applicable.

\section{Availability of data and materials}

The datasets used and/or analysed during the current study are available from the corresponding author on reasonable request.

\section{Competing interests}

None declared.

\section{Funding}

This MPH research was nested in and funded by the South African Research Chair's Initiative of the National Research Foundation and the Department of Science and Innovation. Additional funding was provided by the LESEDI Project funded by Atlantic Philanthropies (Grant ID: 21408).

\section{Author's contributions}

Roshnee Ramsamy (RR) is the principal researcher and the study was part of her Masters of Public Health (MPH). PD and LR are supervisors of the MPH. All authors contributed to the writing, review and editing of the manuscript.

\section{Acknowledgements}

The study was conducted as partial fulfilment of the degree of Master of Public Health (MPH) of Roshnee Ramsamy. Special thanks to Dr Duane Blaauw for statistical support. Thanks and appreciation are extended to Mr Daniel Makoni and Mr Lehlokoana Lepele for their assistance with data access.

\section{References}

1. World Health Organization. Global strategy on human resources for health: Workforce 2030. Geneva: WHO; 2016.

2. Belita A, Mbindyo P, English M. Absenteeism amongst health workers - developing a typology to support empiric work in low-income countries and characterising reported associations. Human Resources for Health. 2013;11(1):1-10. 
3. Dieleman M, Harnmeijer JW. Improving health worker performance: in search of promising practices. Geneva: WHO; 2006.

4. Dovlo D. Wastage in the health workforce: some perspectives from African countries. Human Resources for Health. 2005;3:6.

5. Leao ALM, Barbosa-Branco A, Turchi MD, Steenstra IA, Cole DC. Sickness absence among municipal workers in a Brazilian municipality: a secondary data analysis. BMC Research Notes. 2017;10(1):773.

6. Johnson CJ, Croghan E, Crawford J. The problem and management of sickness absence in the NHS: considerations for nurse managers. Journal of Nursing Management. 2003;11(5):336-42.

7. Wright ME. Long-term sickness absence in an NHS teaching hospital. Occupational Medicine. 1997;47(7):401-6.

8. Public Service Commission. Evaluation of the impact of the Policy and Procedure on Incapacity Leave and III-Health Retirement (PILIR) on sick leave trends in the public service. Pretoria: Public Service Commission; 2010.

9. Naidoo RN, Naidoo S, Hariparsad S. Disabling health: the challenge of incapacity leave and sickness absence management in the public health sector in KwaZulu-Natal Province. In: Padarath A, King J, Mackie E, Casciola J, editors. South African Health Review 2016. Durban: Health Systems Trust; 2016.

10. Department of Public Service and Administration. Policy and Procedure on Incapacity Leave and IIIHealth Retirement. Pretoria; 2009.

11. Kisakye AN, Tweheyo R, Ssengooba F, Pariyo GW, Rutebemberwa E, Kiwanuka SN. Regulatory mechanisms for absenteeism in the health sector: a systematic review of strategies and their implementation. Journal of Healthcare Leadership. 2016;8:81-94.

12. Ticharwa M, Cope V, Murray M. Nurse absenteeism: An analysis of trends and perceptions of nurse unit managers. Journal of Nursing Management. 2019;27(1):109-16.

13. Piha K, Laaksonen M, Martikainen P, Rahkonen O, Lahelma E. Interrelationships between education, occupational class, income and sickness absence. European Journal of Public Health. 2010;20(3):276-80.

14. Merkus SL, van Drongelen A, Holte KA, Labriola M, Lund T, van Mechelen W, et al. The association between shift work and sick leave: a systematic review. Occupational and Environmental Medicine. 2012;69(10):701-12.

15. Ndhlovu CS. Absenteeism in the Gauteng Department of Health: Master's Thesis: University of South Africa (UNISA); 2012.

16. Lees SC. Assessing sick leave absenteeism among public sector workers: a case study of nurses at Groote Schuur Hospital: 2012 and 2013: Master's Thesis: University of the Western Cape; 2015.

17. Gauteng Health pays highest amount to short temporary incapacity applications [press release]. Johannesburg: Gauteng DoH.2017. 
18. Stats SA. Mid Year Population Estimates. Statistics South Africa; 2018.

19. Gauteng Department of Health. Gauteng Department of Health Annual Report 2016/17. Johannesburg: Gauteng DoH; 2017.

20. Kruger WH, Joubert G. Extended sick leave usage in a tertiary hospital over a three-year period. Occupational Health Southern Africa. 2009;Jan/Feb:23-9.

21. Ritchie KA, Macdonald EB, Gilmour WH, Murray KJ. Analysis of sickness absence among employees of four NHS trusts. Occupational and Environmental Medicine. 1999;56(10):702-8.

22. Thorsen SV, Friborg C, Lundstrøm B, Kausto J, Örnelius K, Sundell T, et al. Sickness Absence in the Nordic countries.: Nordic Social Statistical Committee: Copenhagen; 2015.

23. World Health Organization. Developed by women led by men: A gender and equity analysis of the global health and social workforce. Geneva: WHO; 2019.

24. Bekker MH, Rutte CG, van Rijswijk K. Sickness absence: A gender-focused review. Psychology, Health and Medicine. 2009;14(4):405-18.

25. Isah EC, Omorogbe VE, Orji O, Oyovwe L. Self-reported absenteeism among hospital workers in Benin city, Nigeria. Ghana Medical Journal. 2008;42(1):2-7.

26. Tripathi M, Mohan U, Tripathi M, Verma R, Masih La, Pandey HC. Absenteeism among nurses in a tertiary care hospital in India. National Medical Journal of India. 2010;23(3):143-6.

27. Mudaly P, Nkosi ZZ. Factors influencing nurse absenteeism in a general hospital in Durban, South Africa. Journal of Nursing Management. 2015;23(5):623-31.

28. Mollazadeh M, Saraei M, Mehrdad R, Izadi N. Sickness absenteeism of healthcare workers in a teaching hospital. Hospital Practices and Research. 2018;3(1):6-10.

29. Lim A, Chongsuvivatwong V, Geater A, Chayaphum, N, Thammasuwan U. Influence of work type on sickness absence among personnel in a teaching hospital. Journal of Occupational Health. 2002;44(4):254-63.

30. Kristensen TR, Jensen SM, Kreiner S, Mikkelsen S. Socioeconomic status and duration and pattern of sickness absence. A 1-year follow-up study of 2331 hospital employees. BMC Public Health. 2010;10(1):643.

31. Demou E, Smith S, Bhaskar A, Mackay DF, Brown J, Hunt K, et al. Evaluating sickness absence duration by musculoskeletal and mental health issues: a retrospective cohort study of Scottish healthcare workers. BMJ open. 2018;8(1):e018085.

32. Zechinatti AC, Belloti JC, de Moraes VY, Albertoni WM. Occupational musculoskeletal and mental disorders as the most frequent associations to worker's sickness absence: A 10-year cohort study. BMC Research Notes. 2012;5(1):229.

33. Khawaja RA, Sikander R, Khawaja AA, Jareno RJ, Halepota AT. Medically certified sickness absence among health care workers. Journal of the Pakistan Medical Association. 2012;62(9):900-4.

34. Koopmans PC, Roelen CA, Bultmann U, Hoedeman R, van der Klink JJ, Groothoff JW. Gender and age differences in the recurrence of sickness absence due to common mental disorders: a longitudinal 
study. BMC Public Health. 2010;10(1):426.

35. Koopmans PC, Bultmann U, Roelen CA, Hoedeman R, van der Klink JJ, Groothoff JW. Recurrence of sickness absence due to common mental disorders. International Archives of Occupational and Environmental Health. 2011;84(2):193-201.

36. Olivier IPA, Kruger WH, de la Querra A, Joubert G. Low back pain resulting in temporary incapacity leave among South African nurses in the public health sector. Occupational Health Southern Africa. 2018;24(1):9-12.

37. Anderson SP, Oakman J. Allied health professionals and work-related musculoskeletal disorders: a systematic review. Safety and Health at Work. 2016;7(4):259-67. 